\title{
Eradication of two incursions of the Red Imported Fire Ant in Queensland, Australia
}

\author{
By Ross Wylie, Craig Jennings, Melinda K. McNaught, Jane Oakey and Evan J. Harris
}

Of the five known incursions of the bighly invasive Red

Imported Fire Ant in Australia, two are regarded to bave been eradicated. As treatment efforts continue, and the programme evolves and new tools become available, eradication is still considered to be feasible for the remaining Red Imported Fire Ant populations with long-term commitment and support.

Key words: control, eradication, invasive ants, Queensland, Red Imported Fire Ant, Solenopsis invicta.

Ross Wylie is an officer of Biosecurity Queensland, Department of Agriculture and Fisheries, Brisbane, Queensland, Australia and Science Manager for Biosecurity Queensland Control Centre (BQCC) (PO Box 204, Bellbowrie, Qld 4070, Australia; Email: ross.wylie@daf.qld.gov.au; Tel: +61 7 33304621). Craig Jennings is an officer of Biosecurity Queensland, Department of Agriculture and Fisheries, Brisbane, Queensland, Australia and Principal Policy Officer for Plant Biosecurity and Product Integrity, (PO Box 46, Brisbane, Qld 4001, Australia; Email: craig. jennings@daf.qld.gov.au). Melinda K. McNaught is an officer of Biosecurity Queensland, Department of Agriculture and Fisheries, Brisbane, Queensland, Australia and scientist for BQCC (PO Box 204, Bellbowrie, Qld 4070, Australia; Email: melinda.mcnaught@daf.qld.gov.au).Jane Oakey is an officer of Biosecurity Queensland, Department of Agriculture and Fisheries, Brisbane, Queensland, Australia and Principal Molecular

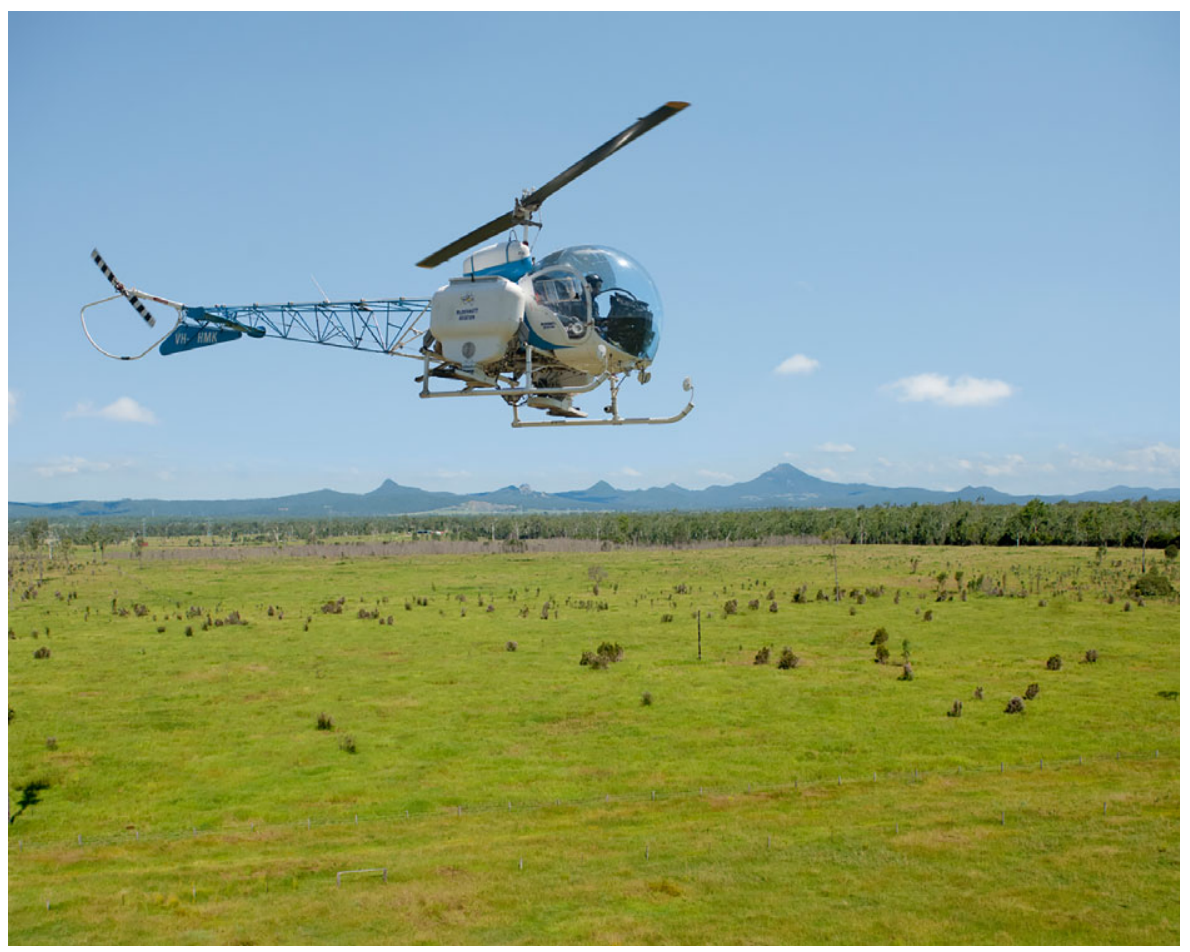

Figure 1. Red Imported Fire Ant readily invades open and disturbed land in both urban and rural areas. Here, a helicopter is using remote sensing to detect potential mounds in grazing land west of Brisbane (photograph: BQCC).

Biologist for Animal Biosecurity and Welfare (Health and Food Science Precinct, 39 Kessels Road, Coopers Plains, Qld 4108, Australia; Email: jane.oakey@daf.qld.gov.au). Evan J. Harris is an officer of Biosecurity Queensland, Department of Agriculture and Fisheries, Brisbane, Queensland, Australia and Laboratory Manager for BQCC (PO Box 204, Bellbowrie, Qld 4070, Australia; Email: evan.harris@daf.qld.gov.au).This paper arose from work carried out for the National Red Imported Fire Ant Eradication Program, based in Brisbane, Australia, and highlights the success of the program.

\section{Introduction}

The Red Imported Fire Ant (Solenopsis invicta Buren) is among the world's worst invasive species (Lowe et al. 2000) and the most notorious of the tramp ants (Fig. 1). Its impacts outside of Australia on wildlife and the environment, agriculture, animal industries, infrastructure, and human health and lifestyle are well documented (Caldwell et al. 1999; Holway et al. 2002; Jetter et al. 2002; Lard 


\section{Box 1. Genetics informs management decisions}

One of the programme's most valuable tools in the effort to eradicate Red Imported Fire Ant from Australia is genetic testing of each new detection. This testing involves both population- and colony-level analysis and is used for a variety of purposes.

Population assignment is used to determine whether a colony belongs to a population already present in Australia or is a new incursion. For example, the 2013 incursion at the Port of Gladstone has been shown to originate from the southern United States while the 2006 incursion at nearby Yarwun came from Argentina. Neither of these incursions were related to the Brisbane populations. Without such information, the programme would have been unable to prove that the Yarwun population was not the result of Red Imported Fire Ant being moved from south-east Queensland, or that the Port of Gladstone population was not the result of treatment failure of the Yarwun population. The software used is Structure (Pritchard et al. 2000) and GenAlEx (Peakall \& Smouse 2006).

Social form is used to determine whether the reproductive form of a colony is monogyne (single queen) or polygyne (multiple queens). Monogyne colonies spread mainly by flight while polygyne colonies mainly spread by budding off a new colony or by movement of infested materials. This knowledge aids in tracing the source of an infestation and assessing the level of risk posed by isolated colonies. It also triggers a different management response in that surveillance buffers for a monogyne detection (with strong-flying founding queens) are greater than for a polygyne detection. The method used is High Resolution Melt PCR (Oakey et al. 2011).

Relatedness between colonies determines relationships between individual Red Imported Fire Ant colonies and can provide information on the number of generations, pedigree, route of spread and mating flight distances. This aids management in targeting treatment and surveillance activities. The software used is Kingroup (Konovalov et al. 2004), Colony (Wang 2004) along with manual confirmation through comparison of alleles.

Bottleneck analysis investigates the level of genetic instability in a population. The remaining Richlands population is showing a decrease in genetic diversity over time, with evidence of inbreeding and fragmentation into subpopulations, which is not seen in other countries invaded by Red Imported Fire Ant. This can be attributed to the pressure being exerted by the eradication programme. The software used is Bottleneck (Cornuet \& Luikart 1996).

et al. 2002; Allen et al. 2004; Tankersley 2008; Vinson 2013). From its native South America (Buren et al. 1974), the Red Imported Fire Ant has spread and become established in the southern United States (Callcott \& Collins 1996), Mexico (Sanchez-Pena et al. 2005), the Caribbean (Davis et al. 2001), Taiwan (Chen et al. 2006) and China (Zhang et al. 2007).

There have been five known incursions of the species on the Australian continent (Fig. 2). Two incursions of Red Imported Fire Ant were discovered in Brisbane, south-east Queensland, in 2001 (Moloney \& Vanderwoude 2002); one in Yarwun, central Queensland, in 2006; one at the Port of Gladstone, central Queensland, in 2013; and one at Port Botany, Sydney, New South Wales, in 2014 (not covered in this paper). All incursions were genetically distinct and unrelated to one another: three of the four Queensland incursions originated from separate populations from the southern United States (Ascunce et al. 2011); the fourth Queensland incur- sion and the Sydney incursion originated from Argentina (BQCC unpublished data).

The discovery of the Brisbane populations in 2001 triggered an emergency response by the then Queensland Department of Primary Industries involving widespread surveillance and tracing of previous movement of highrisk items from infested premises (Moloney \& Vanderwoude 2002; Vanderwoude et al. 2003). Following a scoping study and a cost-benefit analysis strongly favouring eradication (Kompas \& Che 2001), a national response plan to eradicate Red Imported Fire Ant from Australia by June 2006 was endorsed by the Agriculture and Resource Management Council of Australia and New Zealand. Funding was secured through a cost-sharing arrangement between the Commonwealth and State and Territory Governments. The National Red Imported Fire Ant Eradication Program (the programme) commenced in September 2001 with a budget of \$A123 million and over 400 staff. The plan consisted of repeated treatment of infested and putatively infested areas (principally with baits containing insect growth regulators), widespread surveillance, movement controls on materials likely to harbour Red Imported Fire Ant, strong community engagement and supporting research (Moloney \& Vanderwoude 2002; Vanderwoude et al. 2003).

Here, we detail the responses to each of the Queensland incursions, present evidence that two of these incursions (the Port of Brisbane and Yarwun) have been successfully eradicated, and discuss some of the principles and challenges of eradication success within the context of the programme.

\section{The Queensland Eradication Responses}

\section{Port of Brisbane and Richlands populations}

\section{Discovery and locations}

The Port of Brisbane discovery was as a result of stings to a gardener that led 


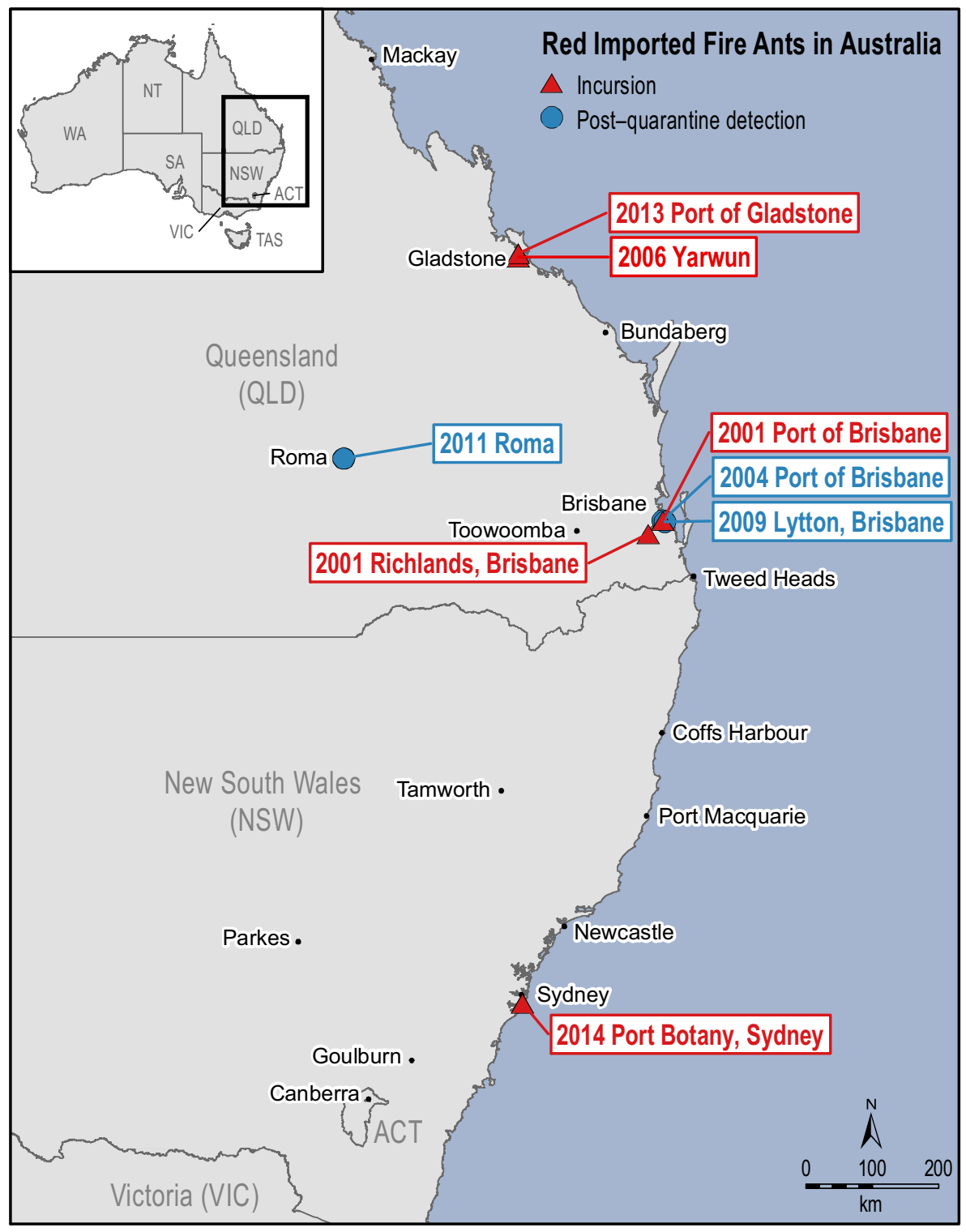

Figure 2. Locations of Red Imported Fire Ant incursions and postquarantine detections in Australia. For details on each detection, see Table 1.

to his hospitalization; the agent responsible was identified as Red Imported Fire Ant (Solley et al. 2002). The Richlands discovery was also gardening related in that a resident was unable to tend her backyard garden because of frequent ant stings, and a visitor from the United States suspected Red Imported Fire Ant, which was subsequently confirmed. Genetic studies have shown that these were two separate incursions originating from the southern United States (Ascunce et al. 2011). Both populations were already well established at the time of discovery in 2001 and it is thought that the ants may have been present in Brisbane for at least 10 years, although this is yet to be proven.

Initial delimitation identified the Port of Brisbane and an area in the south-west centred around Richlands as two separate areas of infestation in Brisbane, together covering over 36000 ha. Tracing resulted in the detection of Red Imported Fire Ant outside these areas, including a small infestation near Cooroy, some $150 \mathrm{~km}$ north of Brisbane (associated with advanced nursery stock), and a consignment of infested plants in Victoria; both were destroyed without having spread further (Vanderwoude et al. 2003).

The Port of Brisbane infestation spanned 19 suburbs, but the epicentre with the highest mound numbers and density was Fisherman Islands (Fig. 3). Scattered infestation (mostly single, isolated colonies) extended up to $12 \mathrm{~km}$ from the epicentre. Initial genetic testing to determine the social form indicated that the Port of Brisbane infestation was solely monogyne (colonies with a single queen) (Henshaw et al. 2005), although this was based on a small number of samples. Later testing of all samples from the Port of Brisbane using a more sensitive laboratory technique (Oakey et al. 2011)

Table 1. Chronology of known Red Imported Fire Ant incursions and postquarantine detections in Australia

\begin{tabular}{llll}
\hline Year & \multicolumn{1}{c}{ Detection } & \multicolumn{1}{c}{ Location } & \multicolumn{1}{c}{ Status } \\
\hline 2001 & Incursion & Port of Brisbane, Qld & Last nest found Feb 2005; declared eradicated in 2012 \\
2001 & Incursion & Richlands, Brisbane, Qld & Eradication in progress \\
2004 & Postquarantine detection & Port of Brisbane, Qld & Destroyed \\
2006 & Incursion & Yarwun, Qld & Last nest found Sept 2006; declared eradicated in 2010 \\
2009 & Postquarantine detection & Lytton, Brisbane, Qld & Destroyed \\
2011 & Postquarantine detection & Roma, Qld & Destroyed \\
2013 & Incursion & Port of Gladstone, Qld & Eradication in progress \\
2014 & Incursion & Port Botany, Sydney, NSW & Eradication in progress \\
\hline
\end{tabular}




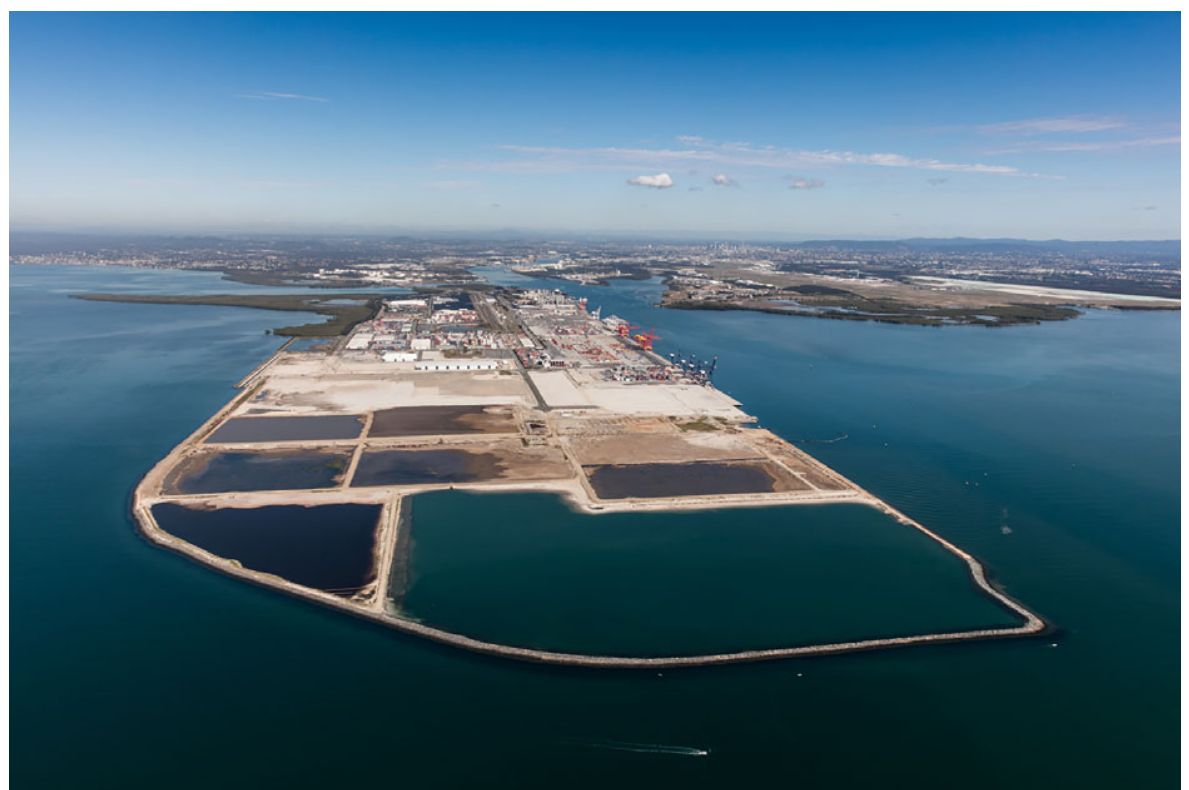

Figure 3. Port of Brisbane, the site of the 2001 incursion of Red Imported Fire Ant. Reclamation works in the foreground are post-2005 (photograph: Port of Brisbane Pty Ltd).

showed the presence of a small number of polygyne (multiple queen) colonies; these polygyne colonies were genetically distinct from the Richlands polygyne colonies, with allelic similarities to the monogyne population present at the Port of Brisbane.

\section{Eradication programmes}

The 5-year eradication plan developed at the start of the programme for the Port of Brisbane involved baiting the entire infested area 3-4 times a year for 3 years. The infested area was delineated by drawing a boundary $2 \mathrm{~km}$ out from all known infested properties. Another boundary was drawn at $5 \mathrm{~km}$, and all of the area between the 2 and $5 \mathrm{~km}$ boundaries received surveillance once a year for 3 years. Following the 3 years of baiting, the treatment area received two rounds of surveillance over 2 years to confirm that eradication had been successful (Jennings 2004). The baits used consisted of defatted corn grit soaked in soybean oil and infused with one of two insect growth regulators (methoprene or pyriproxyfen) or a meta- bolic inhibitor (hydramethylnon). These were delivered by granular spreaders that were either hand held, mounted on ATV quad bikes, or spread from helicopters when treating large areas (Jennings 2004).

The total area treated using the regime described above was $14000 \mathrm{ha}$, including the $2 \mathrm{~km}$ buffers. From November 2001 to April 2004, twelve aerial bait treatments were applied. Because pyriproxyfen cannot be applied aerially within $80 \mathrm{~m}$ of water bodies (according to permitted use of this pesticide), methoprene was used for the majority of bait treatments applied at this time. Two rounds of surveillance were conducted post-treatment, finishing at the end of 2005. The last nest found was in February 2005.

The methodology employed in the early stages for the Richlands population is as described above for the Port of Brisbane. Subsequent changes, made in response to initial results, are described below.

\section{Results}

Eradication at the Port of Brisbane. The progress of the eradi- cation of the Port of Brisbane population between 2001 and 2005 is shown in Figure 4. The Port of Brisbane and Richlands populations remained genetically and spatially distinct throughout this time, separated by distances of $10-15 \mathrm{~km}$. Much of the area between these clusters received structured (ground surveys completed by staff) and passive (samples submitted by the public) surveillance during this period. A few colonies of the Port of Brisbane genotype were found among the Richlands population and vice versa, but these were presumably as a result of movement of infested materials between these areas.

Since the programme commenced in 2001, all sampled Red Imported Fire Ant colonies have been genotyped and subsequently matched to a reference population. No colony has been assigned genotypically to the Port of Brisbane population since 2005, despite ongoing annual surveillance of the port area for Red Imported Fire Ant in addition to broader structured and passive surveillance across Brisbane over the last 10 years. Many staff of the Port of Brisbane Authority received training in surveillance for Red Imported Fire Ant, and there is an officer solely dedicated to this task. In 2010, all areas at the port itself (Fisherman Islands) were surveyed by six fire ant odour detection dogs (a recent addition to the programme) and no Red Imported Fire Ant workers or nests were found.

Following consultation with the national Tramp Ant Consultative Committee (TACC), the technical overview committee for the programme, the Port of Brisbane was removed from the programme's restricted area (the defined area of south-east Queensland where obligations are placed on persons to contain and control Red Imported Fire Ant) (TACC Minutes December 2011). This was recognition that the Port was free of Red Imported Fire Ant, and move- 

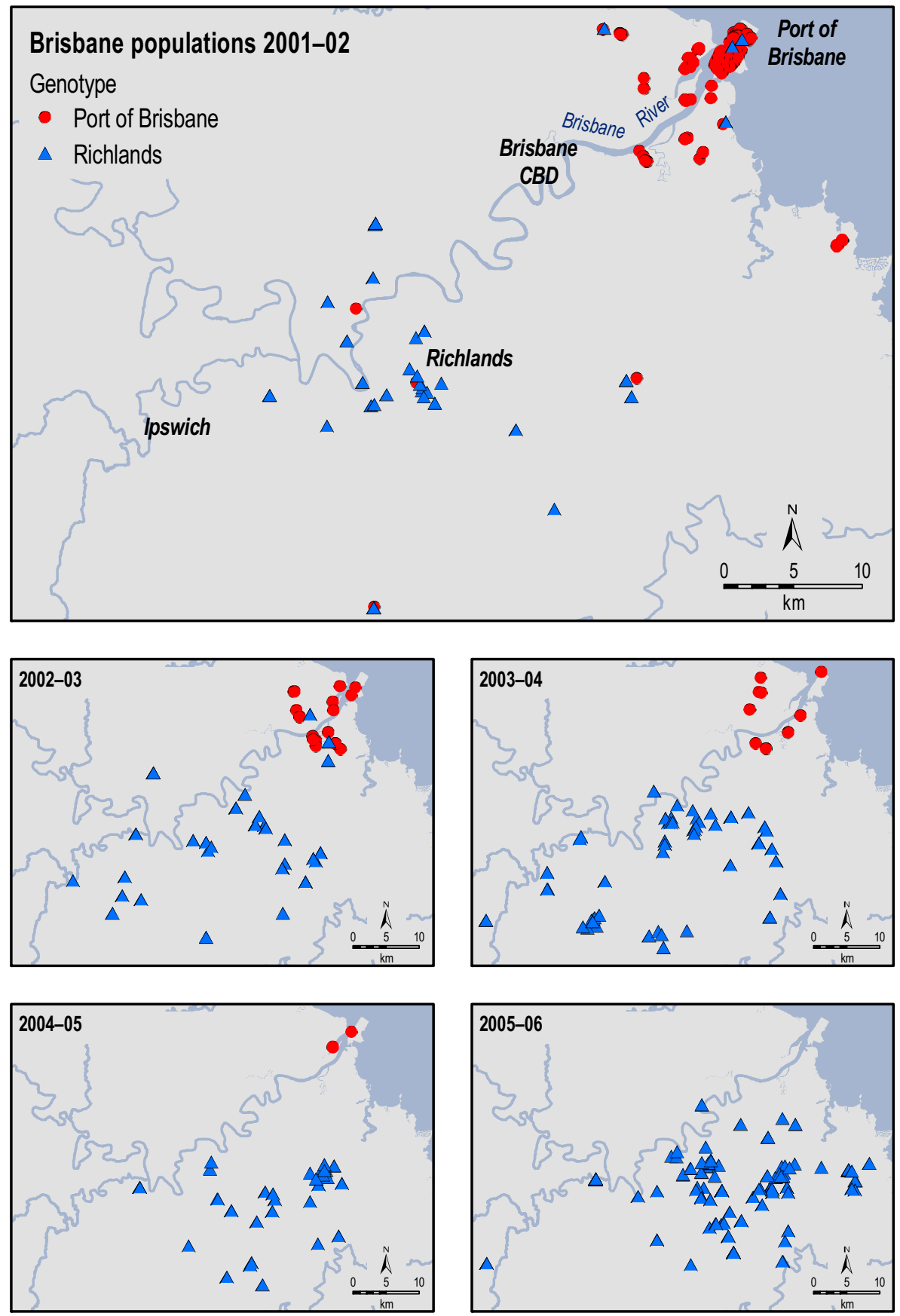

Figure 4. Temporal changes in the distribution of the two populations (Port of Brisbane and Richlands) present in Brisbane at the start of the eradication program. Each point represents a nest where workers were collected for genetic analysis. Distribution is shown for each financial year from 2001-02 to 2005-06.

ment controls were lifted in December 2012. Given that the Port of Brisbane and Richlands populations remained spatially and genetically distinct, and that the Port of Brisbane genotype has not been detected since 2005 despite regular surveillance and genotyping of every Red Imported
Fire Ant detection since then, eradication of the Port of Brisbane population is claimed over a known infested area (determined by drawing a polygon connecting the outermost detected colonies and calculating the enclosed area) of 8300 ha (Fig. 5).
Ongoing efforts at Richlands. Efforts to eradicate the south-west Brisbane population, originally centred on the Richlands area, continue. By the end of 2004, it appeared that the strategy of multiple broadcast bait treatments each year was succeeding and that eradication was on track, with relatively few new colonies detected during that year. Following this, a significant downsizing of the programme occurred at the end of June 2006 in accordance with the agreed response plan, with the workforce reduced from 367 to 164 and the budget reduced from \$A24.5 million to $\$$ A10.2 million. However, in 2007, major new infestations were discovered in a landfill (estimated over 90000 colonies) and in mine rehabilitation sites outside the declared restricted area. New infestation boundaries were declared and treatment programmes commenced, but without commensurate increases in resourcing. In 2009, an independent scientific review concluded that eradication was not possible using current methodology.

In response, a strategy involving suppression and containment was adopted while new tools for delimitation and eradication were developed. Since this time, new tools have been deployed, including remote sensing technology that involves the use of a helicopter carrying thermal, nearinfrared and colour cameras to capture imagery (Fig. 1). This imagery is then analysed with an algorithm to detect potential Red Imported Fire Ant mounds. In addition, statistical predictive models have been developed to highlight areas of suitable habitat and high levels of soil disturbance (favoured by Red Imported Fire Ant founding queens), which guide surveillance and prophylactic treatment. Genetic analysis continues to provide information on the social form (monogyne or polygyne) of new Red Imported Fire Ant detections and determine relatedness between colonies to enable tracing of infestations 


\section{Box 2. Seven features of successful eradication}

Reviews of eradication programmes worldwide have shown that there are seven features that are conducive to successful eradication. These are:

1 Resources must be adequate, and there must be a commitment to see the project through to completion. Most eradication programmes are carried out on a large scale, cost millions of dollars and are sometimes protracted if the pest has a sizeable established foothold before eradication commences.

2 Clear lines of authority must be established. An extensive programme is only feasible if the lead agency has a clear mandate to carry out required procedures at all affected sites.

3 The biology of the species must be appropriate and make it susceptible to control procedures. Detailed scientific knowledge is required of the dispersal ability, reproductive biology and life history of the target species to determine the ease of population reduction.

4 The target species must be detectable at low densities. Early detection can reduce the likelihood of spread, and the ability to detect at low densities is important at the 'tail-end' of an eradication programme.

5 Subsequent intensive management of the system may be necessary, such as restoration following eradication of the target species, if prominent or 'keystone' native species have been removed.

6 Re-invasion must be prevented. Eradication will only be temporary if rapid re-invasion is likely.

7 Protective measures should be in place for rare, threatened or susceptible non-target species and/or habitats.

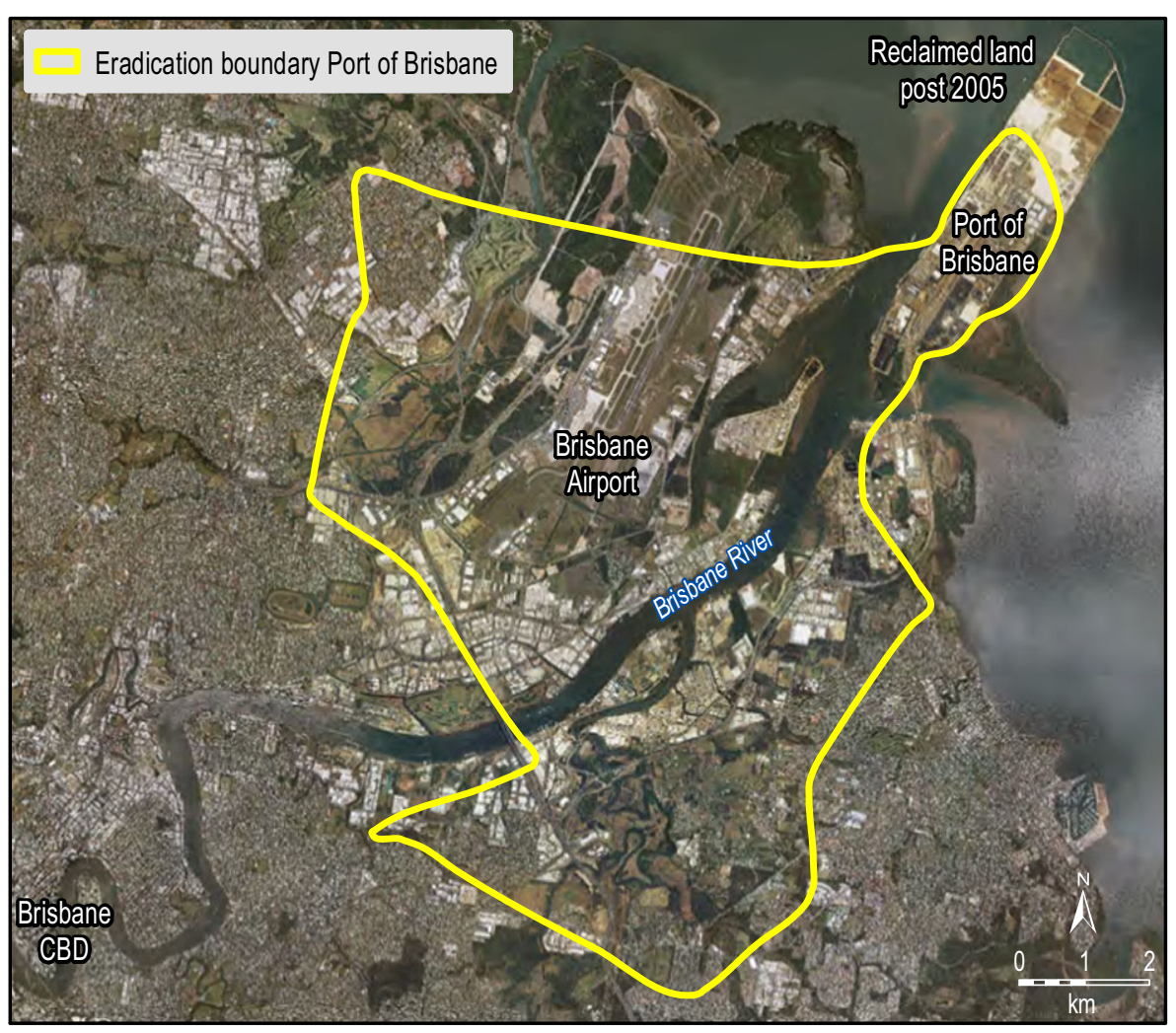

Figure 5. Boundary of eradication of the 2001 Port of Brisbane incursion; the known infested area is 8300 ha.

(Box 1). Continued use of odour detection dogs provides verification that treated areas are free of Red
Imported Fire Ant (Fig. 6). In the financial year 2015-16, the programme is returning to eradication mode.

\section{Yarwun population}

\section{Discovery and locations}

In March 2006, a worker at a commercial chemical manufacturing plant in Yarwun, near Gladstone in central Queensland, reported a suspected Red Imported Fire Ant nest and samples were sent to the Biosecurity Queensland Control Centre in Brisbane for identification. The sample was confirmed as Red Imported Fire Ant and genetic analysis showed that it was a new incursion from Argentina (BQCC unpublished data) and therefore unrelated to the two Brisbane incursions. Delimiting surveillance concentrated on areas of suitable habitat in and around the industrial estate at Yarwun along with possible entry points around the sea port. This surveillance resulted in the detection of infestation on a second land parcel, a mineral refining plant, approximately $1 \mathrm{~km}$ from the first detection. At the chemical manufacturing plant site, mounds were evident in undisturbed areas, but in large areas that were constantly disturbed by construction, only 


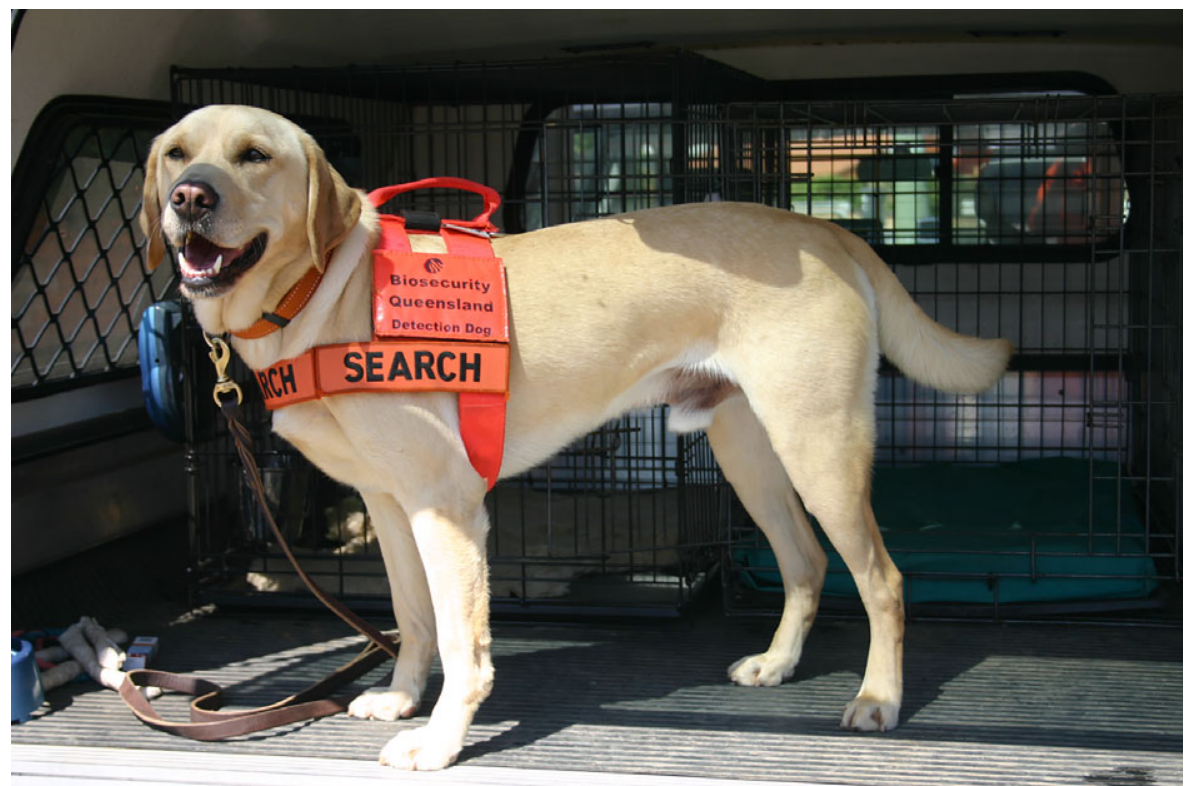

Figure 6. Red Imported Fire Ant odour detection dog 'Clancy' in field harness (photograph: BQCC).

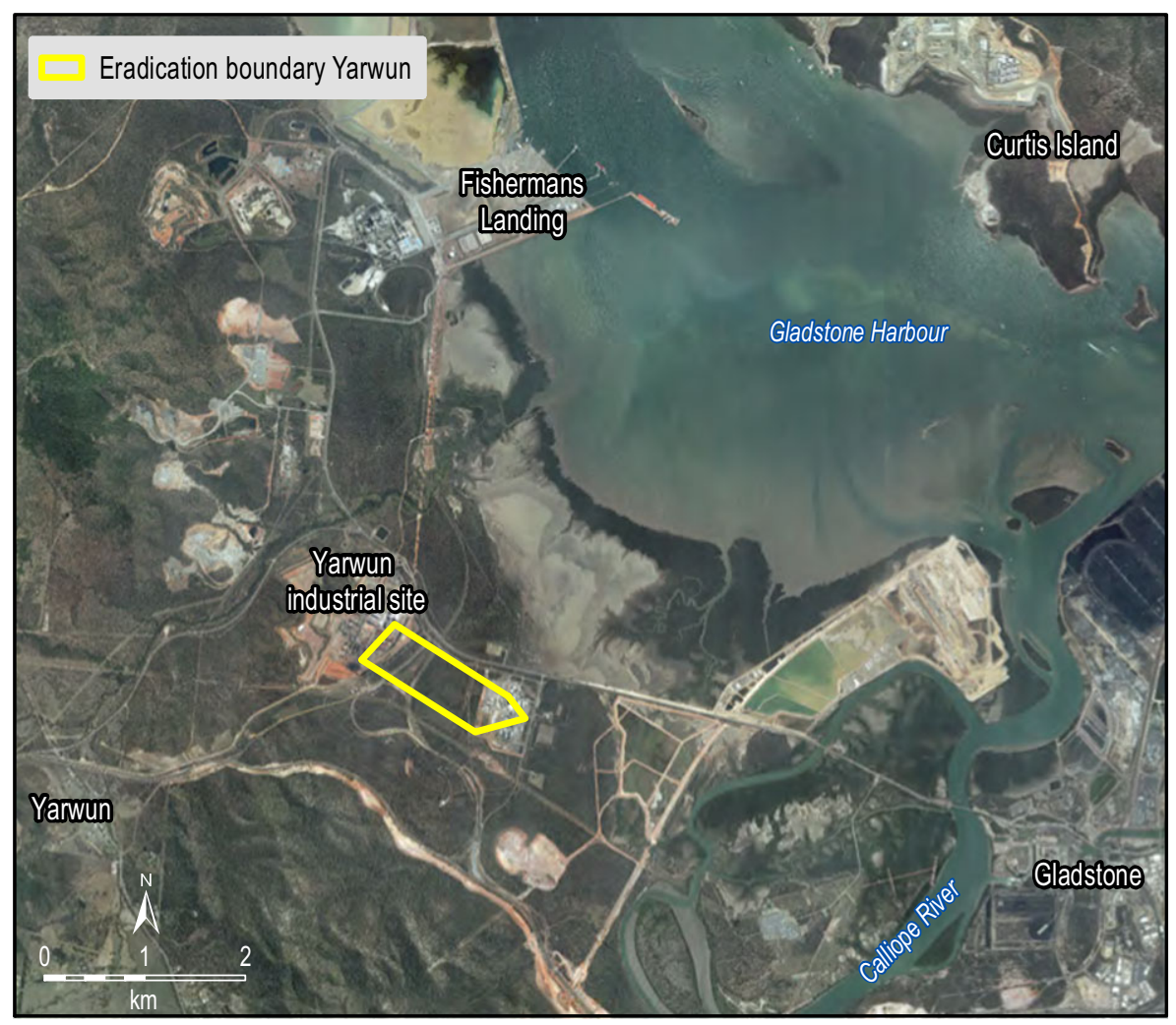

Figure 7. Boundary of eradication of the 2006 Yarwun incursion; the known infested area is 71 ha.

foraging ants were detected. Genetic analysis showed that all Red Imported Fire Ant samples from Yarwun were single queen (monogyne) colonies, and indicated that there were at least 11 colonies present (assuming no inbreeding) with a direct parental link between ants present on both infested land parcels. It was concluded that the incursion was likely to have been founded by at least two Red Imported Fire Ant queens.

\section{Eradication programme}

Following delimiting surveillance, a national 3 year strategy to eradicate Red Imported Fire Ant at Yarwun was adopted. It involved movement controls to limit possible spread of infested material, treatment of all known colonies, surveillance to determine that the treatment had been effective, and surveillance of the area 18 months after the final treatment to confirm eradication from the area. Treatment involved all nests being injected with the contact insecticide fipronil, as well as broadcast baiting of the infested area and surrounds with insect growth regulators.

A treatment area was established with buffers of up to $1 \mathrm{~km}$ from the known infested area where suitable habitat was present; this area totalled 1028 ha. Between May 2006 and November 2007, seven aerial treatments were applied, mainly using pyriproxyfen but with methoprene used near waterways. The two industrial plants were treated by ground application using hand spreaders because aerial treatment at these sites was not permitted.

This response varied from that employed in Brisbane in 2001 in that it was conducted over a shorter time period, involved fewer rounds of treatment, smaller buffers and only a single round of surveillance of the area 18 months after the final treatment to confirm eradication. Reasons for this variation relate to the knowledge gained by the programme in the previous 5 years on the efficacy of the baits (McNaught et al. 2014), the comparatively small area of infestation present at Yarwun and the general unsuitability of habitat for Red Imported Fire Ant. Because of safety considerations at the infested commercial properties, an additional 
round of treatment was applied in lieu of ground surveillance.

\section{Results}

The last Red Imported Fire Ant was found in September 2006. Approximately 18 months after the final treatment (May/June 2009), visual surveillance was conducted by field teams over all suitable habitat within the treatment zone, plus an additional buffer of at least $2 \mathrm{~km}$ around the boundary of the treatment area. No Red Imported Fire Ant nests or workers were detected. In 2010, surveillance by odour detection dogs was conducted at the two land parcels and no Red Imported Fire Ant found. Staff at both commercial properties received training in 2006 in Red Imported Fire Ant identification, and surveillance of the properties by designated personnel in the years following the detection has not detected Red Imported Fire Ant since. In
September 2010, the TACC and its parent National Management Group (NMG) supported the proposal that Yarwun is now free from Red Imported Fire Ant, and that this incursion of Red Imported Fire Ant has been eradicated from Australia (TACC Minutes September 2010; NMG Minutes November 2010). The area of infestation eradicated was 71 ha (Fig. 7).

\section{Port of Gladstone population}

In November 2013, an incursion of Red Imported Fire Ant was detected at commercial premises on recently reclaimed land at Fisherman's Landing, Port of Gladstone (Fig. 8). This site is approximately $4 \mathrm{~km}$ from Yarwun, where the 2006 population was located. Genetic testing showed that this infestation was not related to either of the Brisbane populations or to the 2006 Yarwun infestation. This new incursion was determined to orig- inate from the southern United States and had been present for approximately six generations (a minimum of 3 years). An emergency response was mounted to this new infestation, which covered 220 ha, and is currently ongoing. Surveillance has been conducted out to a radius of $6 \mathrm{~km}$ from the first detected colony, including the previously infested area at Yarwun, totalling more than 6000 ha. During this surveillance, no Red Imported Fire Ant workers belonging to the 2006 Yarwun genotype have been found. The response to the Port of Gladstone incursion is due to finish in July 2016 following completion of the final round of surveillance.

\section{Evaluating Success and Lessons Learned}

The Port of Brisbane and Yarwun case studies show that Red Imported Fire Ant can be eradicated, even over large areas, despite some reservations

\section{Box 3. Possible environmental impacts of Red Imported Fire Ant in Australia}

Much of Australia's flora and fauna is unique as a result of isolation from other major land masses for many millions of years.

Since European settlement, disturbing declines in the biota have already been experienced with many species extinct, endangered or vulnerable. Red Imported Fire Ant, if not eradicated, has the potential to drive further wide-ranging species declines in a variety of habitats.

Native ants influence many aspects of Australian ecosystems, for example, vegetative structure through seed dispersal, seed predation and protection of host plants. While native ants are demonstrating substantial biotic resistance to Red Imported Fire Ant, they are outcompeted and displaced at high densities of the invader with likely adverse effects on ecosystem structure.

Invertebrate communities are likely to be impacted through direct predation, competition for the same resources and interference with symbiotic relationships. Beetle, tick, spider and fly populations may be affected along with land molluscs and several vulnerable butterfly species.

Frog species in Australia likely to be most vulnerable are those that lay their eggs terrestrially under leaf litter or in tunnels in the soil.

Marine turtles are of conservation concern. Fire ants are attracted to turtle nest sites by the disturbance and mucous associated with the digging of the egg chamber and egg laying. Red Imported Fire Ant presence in the nest during hatching can lead to complete mortality of all hatchlings.

Crocodile hatchlings are similarly at risk of fire ant predation, as are lizards in the nesting cavity during hatching.

Birds with terrestrial or low arboreal nests (up to $10 \mathrm{~m}$ above the ground) will be impacted directly through predation of eggs or hatching chicks, and indirectly by the reduction in invertebrate densities (food source) that occurs in areas heavily infested by Red Imported Fire Ant.

Mammal young that shelter in a terrestrial den, and are unable to protect themselves during the early part of their development, are likely to be at risk during this stage. Carnivorous marsupials that rely on larger invertebrates as a food source would be affected by a decline in invertebrate densities caused by Red Imported Fire Ant.

The information in this box has been summarized from Moloney and Vanderwoude (2003). 


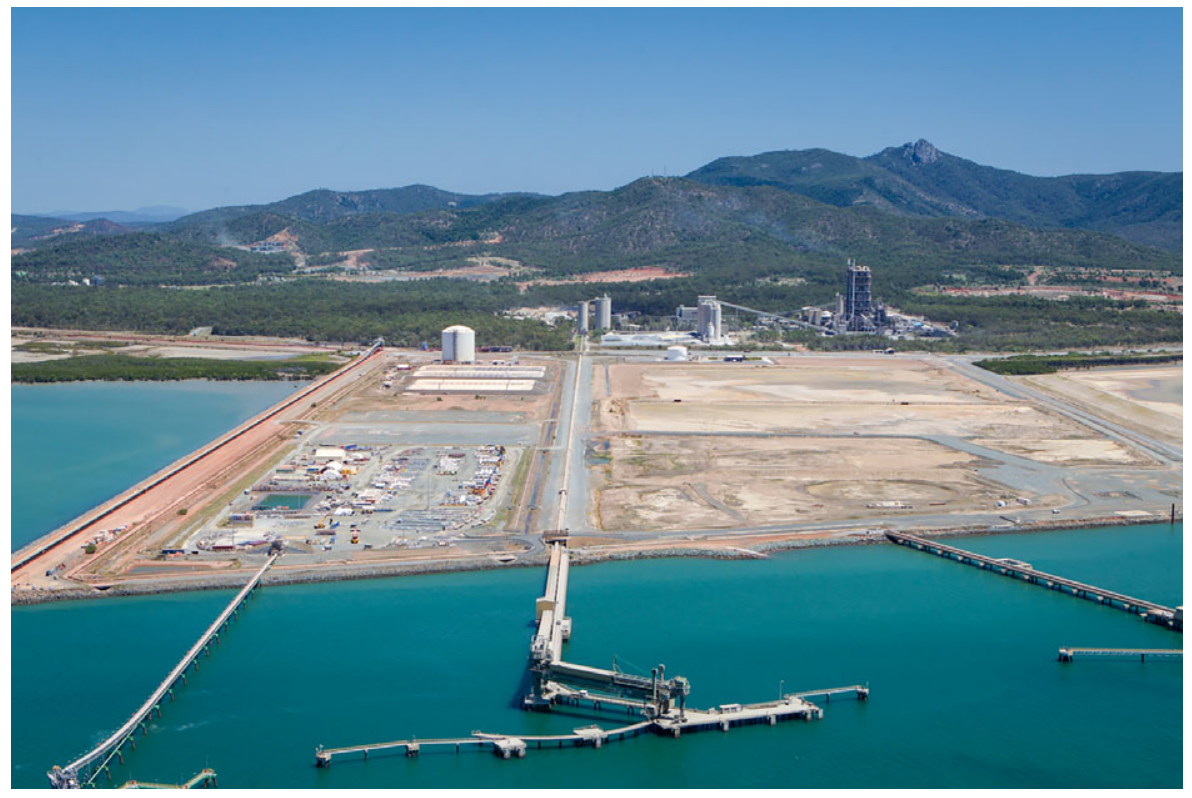

Figure 8. Port of Gladstone, Fisherman's Landing, the site of the 2013 incursion of Red Imported Fire Ant (photograph: BQCC).

about this in the literature (Myers et al. 1998). The previous largest eradication of an ant worldwide was a 300 ha infestation of Argentine Ant, Linepitbema bumile (Mayr), in Western Australia (Van Schagen et al. 1994; Hoffmann et al. 2011). By comparison, the Port of Brisbane infestation was 8300 ha.

Simberloff (2003), Myers et al. (2000), and Hoffmann and O'Connor (2004) between them list seven features that appear to contribute to successful eradication (Box 2). We consider that the Port of Brisbane and Yarwun eradications satisfy all of these criteria, as discussed below.

\section{Resources and commitment}

As discussed by Simberloff (2003), an important fact to consider in any eradication of an invasive species is that killing the first $99 \%$ of a target population can cost less than eliminating the last 1\%. Government agencies may not understand this and may decrease funding once the problem subsides, rather than seeing it through to completion (Mack \& Lonsdale 2002; Simberloff 2003). In Australia, the costsharing partners (Commonwealth and State and Territory governments) have remained committed and have continued to fund the programme for 14 years at a cost to date of \$A320 million. Eradication is still the goal.

\section{Clear lines of authority}

When Red Imported Fire Ant was discovered in Australia in 2001, there were existing structures that allowed for national cost-sharing for eradication, and underlying governance and reporting requirements that provided a clear line of authority for the programme. Queensland had appropriate legislation in place to establish a dedicated control centre that was able to promote and gain broad industry and community acceptance and cooperation.

\section{Biology of the species must be appropriate}

Simberloff (2003) makes the point that with sufficient resources it is possible to eradicate almost any species in a small area; however, the biology of the target species may be crucial. The reproductive biology of the Red Imported Fire Ant means that its invasive potential is high, as monogyne colonies can independently found new colonies by flying unaided up to $5 \mathrm{~km}$, and polygyne colonies can be easily spread by movement of infested materials. It has various other survival and dispersal mechanisms such as adaptations to flooding, which make it a formidable adversary. Nevertheless, in Queensland, McNaught et al. (2014) have shown that repeated bait treatments with approved chemicals applied at appropriate intervals will eliminate both monogyne and polygyne populations of Red Imported Fire Ant.

In addition, the programme exploits certain aspects of the Red Imported Fire Ant's biology in several ways to aid detection. For example, examination of habitat type for every detection of Red Imported Fire Ant in south-east Queensland since 2001 has facilitated the construction of a 'habitat model', which is used to guide surveillance for the pest. The preference of Red Imported Fire Ant for disturbed ground is well known (Tschinkel 2006), and the programme also uses a 'disturbance model', employing Landsat imagery, to identify sites that could potentially become infested and would be suitable for prophylactic treatment. Red Imported Fire Ant mounds, with their honeycomb internal structure, tend to become hotter than the surrounding soil (up to $20-30^{\circ} \mathrm{C}$ warmer), and this thermal differential can be detected in imagery collected using remote sensing. In the cooler months, remote sensing is being used to survey for Red Imported Fire Ant mounds over large areas.

\section{Target species must be detectable at low densities}

The programme currently has nine Red Imported Fire Ant odour detection dogs and three handlers. The efficacy of the dogs in detecting Red Imported Fire Ant is high (almost $100 \%$ as determined by field trials), as they can detect a single foraging 
ant in the field. The dog teams are used for targeted surveillance efforts and to validate treatment success.

\section{Restoration}

Removing an exotic species using pesticides often has unforseen and undesirable side effects, such as removal of other important members of an ecological community (Simberloff 2003). The baits used by the programme contain pyriproxyfen and methoprene; these chemicals have been in use worldwide for many years and known environmental side effects are minimal if used according to the labels. McNaught et al. (2014) showed that the baits had little effect on the local ant fauna and only one genus, Pbeidole, was affected in a similar way to Red Imported Fire Ant. In addition, Pbeidole spp. began returning to the study plots at the cessation of the baiting programme (BQCC unpublished data).

\section{Reinvasion}

The distinction between eradication and control blurs when there is a continual threat of re-entry by invasive species (Mack \& Lonsdale 2002). To date, in addition to the five known incursions of Red Imported Fire Ant in Australia, there have been three known postquarantine detections of Red Imported Fire Ant into Queensland (Table 1). These detections were dealt with before they could establish: one was detected in 2004 in a shipping container at the Port of Brisbane; one in 2009 in a shipping container in the Brisbane suburb of Lytton; and another in 2011 at Roma west of Brisbane in a crate of mining equipment from Texas, United States. The response to the New South Wales incursion at Port Botany in Sydney, which genetic analysis indicated to have originated in Argentina, is progressing well with no Red Imported Fire Ant detected in delimiting surveillance since the initial discovery of a single colony in November 2014.
Australia has stringent biosecurity at ports-of-entry (Stanaway et al. 2001) and conducts profiling of likely pathways of Red Imported Fire Ant from other infested countries. Containers and second-hand earth-moving equipment that may carry soil are targeted. However, in the case of the postborder intercept discovered in Roma, Red Imported Fire Ant queens entered via a consignment of new equipment in a crate free of soil, transported by air from Texas to Brisbane via Singapore, then by road to Roma within a week. Further detections may be expected, but measures are in place to improve the targeting of potential pathways for invasive ants into the country.

\section{Protective measures for rare, threatened or susceptible nontarget species and/or habitats}

Red Imported Fire Ant has been categorized as a pest of agriculture, but the more serious impacts of Red Imported Fire Ant in Australia, should eradication fail, will be on the environment and on health and lifestyle. Unfortunately, apart from some initial input through a cross-agency taskforce and Environmental Advisory Panel, neither the environment nor the health sectors have significantly engaged over the life of the programme. In the United States, wildlife such as hatching turtles, alligators, birds, skinks, frogs, lizards, small mammals and many invertebrates have been impacted by fire ants (Jetter et al. 2002; Allen et al. 2004). Similar impacts are likely in Australia if the ant becomes widespread, as outlined by Moloney and Vanderwoude (2003) (Box 3). In 1985, in the United States, it was estimated that approximately 14 million people are stung by fire ants each year and more than 80000 require medical attention (Adams 1986); three people have died from fire ant stings in the last 18 months. Australia has not yet experienced such severe impacts due to the success of the programme in eradicat- ing or greatly reducing Red Imported Fire Ant populations. No adverse environmental impacts of the bait treatments used by the programme have been recorded (see above). However, we believe a broader coalition of stakeholders in Australia is required to deal with this pest.

\section{Conclusion}

Of the five known established incursions of Red Imported Fire Ant in Australia, two have been eradicated (the Port of Brisbane and Yarwun) and three are in the process of being eradicated. The eradication of a population of Red Imported Fire Ant from 8300 hectares at the Port of Brisbane is the largest such recorded for any ant species. Importantly, it demonstrates the technical feasibility of Red Imported Fire Ant eradication over large areas. What is required now for the remaining populations in Australia is recognition by governments that eradication may still be a long way off but is achievable, and there needs to be a commitment of adequate resources to that goal.

\section{Acknowledgements}

We are grateful to past and present staff of the Biosecurity Queensland Control Centre who were involved in the collection of data used in this study, and thank Penny Flannigan and Mark Fawkes for preparing the maps. We thank Dr Ben Hoffmann, CSIRO, Darwin for his advice and helpful comments on this manuscript. We acknowledge the financial support provided to the National Red Imported Fire Ant Eradication Program by the Australian Commonwealth, States and Territories.

\section{References}

Adams C. T. (1986) Agricultural and medical
impact of the imported fire ants. In: Fire Ants
and Leaf Cutting Ants: Biology and Manage-
ment. (eds C. S. Lofgren and R. K. Vander
Meer) pp. 48-57. Westview Press, Boulder. 
Allen C. R., Epperson D. M. and Garmestani A. S. (2004) Red imported fire ant impacts on wildlife: a decade of research. American Midland Naturalist 152, 88-103.

Ascunce M. S., Yang C.-C., Oakey J. et al. (2011) Global invasion history of the fire ant Solenopsis invicta. Science 331, 10661068.

Buren W. F., Allen G. E., Whitcomb W. H., Lennartz F. E. and Williams R. N. (1974) Zoogeography of the imported fire ants. Journal of the New York Entomological Society 82. 113-124.

Caldwell S. T., Schuman S. H. and Simpson W. M. (1999) Fire ants: a continuing community health threat in South Carolina. Journal of the South Carolina Medical Association 95, 231-235.

Callcott A. M. A. and Collins H. L. (1996) Invasion and range expansion of imported fire ants (Hymenoptera: Formicidae) in North America from 1918-1995. Florida Entomologist 79, 240-251.

Chen J. S. C., Shen C.-H. and Lee H.-J. (2006) Monogynous and polygynous red imported fire ants, Solenopsis invicta Buren (Hymenoptera: Formicidae), in Taiwan. Environmental Entomology 35, 167-172.

Cornuet J. M. and Luikart G. (1996) Description and power analysis of two tests for detecting recent population bottlenecks from allele frequency data. Genetics 144, 2001-2014.

Davis L. R. J., Vander Meer R. K. and Porter S. D. (2001) Red imported fire ants expand their range across the West Indies. Florida Entomologist 84, 735-736.

Henshaw M. T., Kunzmann N., Vanderwoude C., Sanetra M. and Crozier R. (2005) Population genetics and history of the introduced fire ant, Solenopsis invicta Buren (Hymenoptera: Formicidae), in Australia. Australian Journal of Entomology 44, 37-44.

Hoffmann B. and O'Connor S. (2004) Eradication of two exotic ants from Kakadu National Park. Ecological Management and Restoration 5 98-105.

Hoffmann B., Davis P., Gott K. et al. (2011) Improving ant eradications: details of more successes, a global synthesis and recommendations. Aliens 31, 16-23.

Holway D. A., Lach L., Suarez A. V., Tsutsui N. D. and Case T. J. (2002) The causes and consequences of ant invasions. Annual Review of Ecology and Systematics 33, 181-233.

Jennings C. (2004) A brief history of the red imported fire ant eradication program. The Australian Journal of Emergency Management 19, 97-100.
Jetter K. M., Hamilton J. and Klotz J. H. (2002) Red imported fire ants threaten agriculture, wildlife and homes. California Agriculture 56, 26-34.

Kompas T. and Che N. (2001) An Economic Assessment of the Costs of Red Imported Fire Ants in Australia. Consultancy Report to Queensland Department of Primary Industries, Australian Bureau of Agricultural and Resource Economics, Canberra.

Konovalov D., Manning C. and Henshaw M. (2004) Kingroup: a program for pedigree relationship reconstruction and kingroup assignments using genetic markers. Molecular Ecology Notes 4, 779-782.

Lard C., Willis D. B., Salin V. and Robison S. (2002) Economic assessments of red imported fire ant on Texas' urban and agricultural sectors. Southwestern Entomologist 41, 123-137.

Lowe S., Browne M., Boudjelas S. and De Poorter M. (2000) 100 of the World's Worst Invasive AlienSpecies: A selection from the Global Invasive Species Database. Published by The Invasive Species Specialist Group. [Accessed 05 August 2015.] Available from URL: http://www.issg.org/pdf/publications/ worst 100/english 100 worst.pdf.

Mack R. N. and Lonsdale W. M. (2002) Eradicating invasive plants: hard won lessons for islands. In: Turning the Tide: Eradication of Invasive Species, Proceedings of the International Conference on Eradication of Island Invasives. (eds D. Veitch and M. Clout) pp. 164-172. IUCN, Gland, Switzerland.

McNaught M. K., Wylie F. R., Harris E. J., Alston C. L., Burwell C. J. and Jennings C. (2014) Effect of broadcast baiting on abundance patterns of red imported fire ants (Hymenoptera: Formicidae) and key local genera at long-term monitoring sites in Brisbane, Australia. Journal of Economic Entomology 107, 13071315.

Moloney S. and Vanderwoude C. (2002) Red imported fire ants: a threat to eastern Australia's wildlife? Ecological Management and Restoration 3, 167-175.

Moloney S. and Vanderwoude C. (2003) Potential ecological impacts of red imported fire ants in eastern Australia. Journal of Agricultural and Urban Entomology 20, 131-142.

Myers J. H., Savoie A. and Van Randen E. (1998) Eradication and pest management. Annual Review of Entomology 43, 471-491.

Myers J. H., Simberloff D., Kuris A. M. and Carey J. R. (2000) Eradication revisited: dealing with exotic species. Trends in Ecology and Evolution 15, 316-320.
Oakey J., Harris E. J., Pease B., Jennings C. and McCubbin K. (2011) Differentiation of Solenopsis invicta social forms using high resolution melt PCR. Bulletin of Entomological Research 101, 581-589.

Peakall R. and Smouse P. (2006) Genalex6: genetic analysis in Excel. Population genetic software for teaching and research. Molecular Ecology Notes 6, 288-295.

Pritchard J., Stephens M. and Donnell P. (2000) Inference of population structure using multilocus genotype data. Genetics 155, 945959.

Sanchez-Pena S. R., Patrock R. J. W. and Gilbert L. A. (2005) The red imported fire ant is now in Mexico: documentation of its wide distribution along the Texas-Mexico border. Entomological News 116, 363-366.

Simberloff D. (2003) Eradication-preventing invasions at the outset. Weed Science Society of America 51, 247-253.

Solley G. O., Vanderwoude C. and Knight G. K. (2002) Anaphylaxis due to red imported fire ant sting. Medical Journal of Australia 176. 521-523.

Stanaway M. A., Zalucki M. P., Gillespie P. S. and Rodriquez C. M. (2001) Pest risk assessment of insects in sea cargo containers. Australian Journal of Entomology 40, 180-192.

Tankersley M. S. (2008) The stinging impact of the red imported fire ant. Current Opinion in Allergy and Clinical Immunology 8, 354-359.

Tschinkel W. R. (2006) The Fire Ants. Harvard University Press, Cambridge, USA.

Van Schagen J. J., Davis P. R. and Widmer M. A. (1994) Ant pests of Western Australia, with particular reference to the Argentine Ant (Linepithema humile). In: Exotic Ants: Biology, Impact, and Control of Introduced Species. (ed D. F. Williams) pp. 174-180. Westview Press, Boulder, USA.

Vanderwoude C., Elson-Harris M., Hargreaves J. R., Harris E. J. and Plowman K. P. (2003) An overview of the red imported fire ant (Solenopsis invicta Buren) eradication plan for Australia. Records of the South Australian Museum Monograph Series 7, 11-16.

Vinson S. B. (2013) Impact of the invasion of the imported fire ant. Insect Science 20, 439455.

Wang J. (2004) Sibship reconstruction from genetic data with typing errors. Genetics 166. 1963-1979.

Zhang R., Li Y., Liu N. and Porter S. D. (2007) An overview of the red imported fire ant (Hymenoptera: Formicidae) in mainland China. Florida Entomologist 90, 723-731. 